
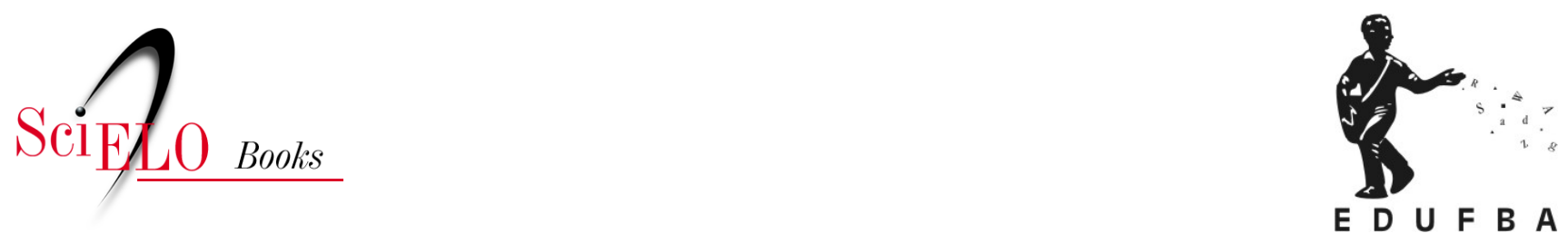

\title{
O Hip-hop não para!
}

\author{
Rebeca Sobral Freire
}

\section{SciELO Books / SciELO Livros / SciELO Libros}

FREIRE, R.S. O Hip-hop não para! In: Hip-hop feminista? Convenções de gênero e feminismos no movimento Hip-hop soteropolitano [online]. Salvador: EDUFBA/NEIM, 2018. Bahianas collection, $\mathrm{n}$. 20, pp. 43-76. ISBN: 978-85-232-1862-1. https://doi.org/10.7476/9788523218621.0004.

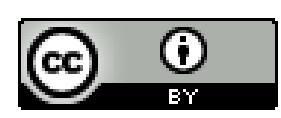

All the contents of this work, except where otherwise noted, is licensed under a Creative Commons Attribution $\underline{4.0 \text { International license. }}$

Todo o conteúdo deste trabalho, exceto quando houver ressalva, é publicado sob a licença $\underline{\text { Creative Commons }}$ Atribição 4.0.

Todo el contenido de esta obra, excepto donde se indique lo contrario, está bajo licencia de la licencia Creative Commons Reconocimento 4.0. 


\section{O HIP-HOP NÃO PARA! ${ }^{14}$}

A partir da produção de uma ciência feminista ou de uma perspectiva feminista de ciência (SARDENBERG, 2002), configura-se o surgimento de uma teoria feminista que dialoga com as diversas experiências das mulheres e colabora com a análise das relações sociais de gênero nas quais elas estão envolvidas. Essa necessidade teórica de uma ciência feminista que considere os diferentes olhares sobre as mulheres, por sua vez, abrange algumas questões, como: o próprio questionamento acerca das manifestações do patriarcado e suas percepções; a quebra de um pensamento universal em termos das diversidades; e a ruptura com conceitos que hierarquizam as relações entre o masculino e o feminino.

Neste sentido, a construção de um pensamento feminista se constitui no diálogo da teoria com a prática cotidiana da vida das diversas mulheres em suas distintas configurações e relações. Para tanto, Maria Betânia Ávila (2000) define o feminismo pela composição entre prática política e pensamento crítico. Para autora,

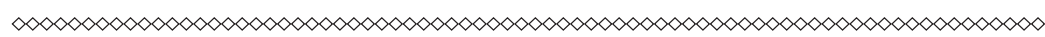

14 Este título pode ser considerado um dos lemas do hip-hop e traduz a resistência e persistência do movimento em sua luta, sentimento que compartilho na realização deste trabalho. 
Movimento Feminista é aquele que tem como perspectiva a transformação das relações de gênero, cujo foco de atuação é a luta por liberdade e igualdade para as mulheres, o que o torna um movimento contra a exploração e a dominação às quais estão sujeitas as mulheres. (ÁVILA, 2000, p. 6)

Pode-se compreender o feminismo como um projeto político que visa construir uma balança de equilíbrio de poder entre homens e mulheres, e, portanto, capaz de dar conta de reparar as desigualdades sociais referentes às relações de gênero. (COSTA; SADENBERG, 1994) Por gênero se compreende as relações sociais entre homens e mulheres, mulheres e mulheres, e homens e homens, em suas diversas possibilidades de interação, não podendo ser esse conceito usado como um sinônimo de mulheres.

Segundo Joan Scott (1992, p. 3), a compreensão da importância de gênero como categoria útil "exige a análise não só da relação entre experiências masculinas e femininas no passado, mas também a ligação entre a história do passado e as práticas históricas atuais". A partir do conceito trabalhado pela autora, dois pontos são relevantes para pensar gênero: 1) É o elemento fundamental das relações entre os diferentes sexos; e 2) Dá significado às relações de poder.

Isso pode ser explicado diante de alguns questionamentos fundamentais acerca dessas relações, que apenas podem ser respondidos através da análise da categoria gênero: como é que o gênero funciona nas relações sociais humanas? Como o gênero pode dar sentido à organização e à percepção do conhecimento histórico em diferentes épocas?

A partir dessa conceituação, as mulheres e os homens estariam inseridos em relações recíprocas e não mais de formas separadas ou naturalizadas. Essa separação entre homens e mulheres, ambos sujeitos políticos, é bem explicada por Maria Noemi Castilhos Brito (2001, p. 291): 
Historicamente, a construção das identidades de homens e mulheres se tem configurado a partir da dicotomia entre as esferas públicas e privadas, com atribuições de papéis, atitudes e valores previamente definidos segundo modelos naturais.

Portanto, essa identidade de gênero é construída social e culturalmente em cada sociedade em seu respectivo tempo e espaço.

É o que Maria Betânia Ávila (2000) explica quando defende o entendimento sobre a relação igualdade-diferença não como antagônica, mas como um dilema a ser enfrentado como parte do processo dialético da transformação social. Entretanto, chama atenção para a base de relações sociais desiguais na qual não se sustenta o ideal de igualdade, a exemplo de gênero. Ou seja, gênero atua em um campo em movimento, no qual estão reconhecidas as relações de poder em constante disputa, negociação e reconfigurações nos diversos âmbitos e espaços da sociedade. Dadas as dimensões, são as convenções sociais capazes de fornecer um "valor filosófico" a gênero.

Contudo, gênero abrange duas dimensões extremamente caras a esta análise. São as dimensões do simbólico (significados da cultura) e do político. De acordo com Alinne Bonetti (2003, p. 185):

A categoria analítica gênero articula concepção cultural e historicamente situadas, partindo, portanto, dos significantes disponíveis na cultura. Estes significantes são apropriados pelos sujeitos sociais, os quais lhes atribuem determinados sentidos.

Os significantes encontrados na cultura, que podem ser materiais e/ou imateriais e dão significado ao que é visto através do gênero, como se vestissem ou dessem significado a gênero. Assim, as relações sociais podem ser entendidas a partir das convenções de gênero. Em sua tese, a partir de uma perspectiva etnográfica feminista e que se desenvolve em um campo nordestino, "Não basta ser mulher, tem de ter coragem - Uma etnografia sobre 
gênero, poder, ativismo feminino popular e o campo político feminista de Recife - PE”, Alinne Bonetti (2007, p. 27) possibilita identificar as convenções de gênero particulares que

adotam de sentido as práticas políticas em embate, bem como os diferentes repertórios simbólicos que compõem o contexto politico em questão e nele se antagonizam. Possibilita o desvendamento de novas potencialidades para a compreensão das práticas políticas feministas.

Consequentemente, é a partir da cultura que se formam os valores, que, posteriormente, influenciam a construção dos sujeitos sociais. (BONETTI, 2003) Vale ressaltar que este processo de construção se dá diante de um contexto de desigualdades sociais.

De acordo com Donna Haraway (1995), há uma necessidade de compreensão de como significados e corpos são construídos. Para tanto, a autora defende o desenvolvimento de "saberes localizados”, não redutíveis, mas parciais diante de uma experiência corporificada. Para ela, estes "saberes localizados" significam uma objetividade feminista e corporificada que se inscreve como uma escrita feminista do corpo, portanto, limitada, parcial e situada. Essa ideia está atrelada ao fato de nos tornarmos responsáveis pelo que aprendemos a ver e pelo conhecimento que produzimos.

Já gênero, em sua dimensão do político, assume um caráter social, que denomina as relações de poder entre os sexos. Para tanto, gênero promove a distinção baseada no sexo, a fim de refutar o determinismo biológico implícito no uso de termos como "sexo" ou "diferença sexual". Além disso, essa categoria destaca o aspecto relacional das definições normativas da feminilidade e da masculinidade, que são construídos socialmente em distintos tempo e lugar.

Portanto, gênero utilizado sob uma perspectiva feminista permite a promoção de uma ruptura do binômio cultura-biologia, relacionado, respectivamente, a homem-mulher e público-privado. 
(ÁVILA, 2007) Ruptura essa importante por ampliar o entendimento sobre a definição do que é política a partir do diálogo entre as esferas pública e privada, anteriormente distintas e separadas.

O político se configurou em uma nova forma, de modo a ampliar a esfera pública capaz de abarcar a esfera privada. É o que aponta Maria Noemi Castilhos Brito (2001, p. 296) ao destacar as "novas dimensões para política e novas práticas significativas em outros níveis além do tradicional”, incorporadas a esse conceito, que não aceitam a representação do homem como sujeito universal atuante da esfera pública nem representante do político, além de reconhecer o político dentro da própria esfera privada e a interação entre ambas as esferas, pública e privada. O antigo binarismo público-privado não daria conta de explicar a realidade histórica vivenciada pelos sujeitos políticos e suas relações.

Para tanto, aprofundando a discussão sobre o campo do político como suporte para embasar este estudo, me apoio na compreensão de Sônia Alvarez (1998), a partir de seu artigo "Feminismos latinomericanos", estando em debate o campo político feminista a partir da experiência da América Latina. A autora propõe uma distinção entre o campo da "política" e o campo do "político".

Em sua definição, o campo da política é entendido como uma esfera da política mais clássica, tratada em seu sentido mais geral, enquanto a política pública trata de uma esfera mais específica. (ALVAREZ, 1998) Esse sentido mais clássico se circunscreve à instituições políticas, partidos políticos, cargos de representação política, espaços de atuação. (BONETTI, 2003) Como exemplo de alguns destes espaços ou canais de atuação estão os conselhos de direitos ou mesmo movimentos sociais e organizações não governamentais (ONGs).

Já o campo do político atual é "O sentido mais amplo de decidir sobre o cultural, o simbólico, e as relações de poder/gênero que 
ali são constituídos e continuamente reconfigurado". (ALVAREZ, 1998, p. 167 $)^{15}$ É nesse campo, interessado nos aspectos culturais e simbólicos, que se insere esta pesquisa, na interface entre "o gênero e o político" a partir da experiência das mulheres e seus "atributos de gênero" encontrados.

Segundo Alinne Bonetti (2003), o campo do político é eminentemente masculino; ao considerar seus valores e atributos de gênero, associam culturalmente o masculino ao modelo de sujeito dominante. Essa posição pode ser compreendida pela definição de Pierre Bourdieu (2007) para o campo político como um campo de forças, um campo de lutas em que relações e estruturas estão em disputa em um dado momento. Para o autor, é no campo político que são gerados produtos - entre eles, problemas, programas, análises, comentários, conceitos, acontecimentos - como "instrumentos de percepção e expressão do mundo social”, ou princípios de divisão, ou mesmo onde se dá a distribuição de opiniões (efeitos de censura entre o que é dizível ou não).

Portanto, é no campo do político em que se disputam as visões de mundo e se configuram gênero e suas convenções, havendo uma espécie de hegemonia (no sentido de direção) de um modelo de visão de mundo, no qual se definem comportamentos, valores, opções de consumo e etc. Essa visão de mundo que privilegia o masculino está em disputa dentro desse campo a partir da dinâmica de gênero vivida na sociedade, sob uma lógica de reciprocidade e troca social entre o feminino e o masculino.

É o que mostra a pesquisa de Alinne Bonetti (2004) ao investigar a atuação das Promotoras Legais Populares do Partenon (PLP), em bairro de Porto Alegre, em 1999. Segundo a autora,

Estudos sobre as concepções acerca do político entre grupos populares urbanos brasileiros revelam que a lógica

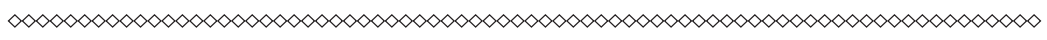
15 "En el sentido más amplio de incidir en lo cultural, lo simbólico, y en las relaciones de poder/ de género que alí se constituyen y se reconfiguran continuamente". 
de reciprocidade que informa as visões de mundo é estendida também ao mundo das relações políticas. A partir disso, salienta-se que o político adquire um significado particular dentro da lógica simbólica do grupo. (BONETTI, 2004, p. 136)

Contudo, o político do conceito de gênero é usado como ferramenta de análise de caráter interdisciplinar, em que "gênero" é assumido como uma categoria relacional para distinguir as configurações das relações de gênero vivenciadas na sociedade e/ou em um campo específico a ser analisado, estando inclusive aberto para considerações acerca da interação com outras categorias de análise a exemplo de raça/etnia, classe social, orientação sexual, sexualidade, idade/geração, dentre outras.

Para tanto, gênero apresenta-se como um conceito capaz de auxiliar estudos no campo da participação das mulheres e das convenções de gênero em experiências com o feminismo e o movimento social constituídos por segmentos de jovens.

Como exemplo do campo estudado, as hip hoppers (mulheres no hip-hop) revelam sua participação no movimento Hip-hop enquanto prática política a partir da exposição de demandas políticas das mulheres para o movimento e para a sociedade. (FREIRE, 2010) Em suas rimas, desenhos e iniciativas, expressam os desafios enfrentados pelas jovens que, no espaço público e privado, se deparam com formas de preconceito e discriminação por sua condição feminina. A partir de suas experiências, essas jovens reformulam os interesses do Hip-hop ao inseririrem pautas específicas na agenda política desse movimento. Para tanto, faz-se necessária a atenção a algumas categorias relevantes para se compreender esse fenômeno de forma mais completa.

Por isso, a necessidade de uma maior atenção para a categoria "geração" nos estudos de gênero e feministas é reconhecida e criticada pela socióloga Alda Britto da Motta (2004, p. 353), que afirma ser essa uma questão "quase invariavelmente omitida". 
Assim, é tratada a categoria "mulher adulta" como um sujeito universal nesse campo de estudo, configurando um "adultocentrismo", subalternizando outros segmentos atuantes no próprio movimento social de mulheres e/ou feministas.

Vale ressaltar que os primeiros estudos que referendaram especificamente a categoria juventude e visibilizaram essa participação tiveram início no contexto político dos anos de 1960 e 1970, influenciados pela experiência de participação dos movimentos sociais. (MOTTA, 2004) Esses movimentos foram representados em diversas ações em diferentes lugares do mundo, a exemplo do movimento Hippie, das mobilizações contra a Guerra do Vietnã, da "segunda onda" do feminismo, do movimento Estudantil e do movimento Negro. Essa geração até recentemente é reconhecida, e assim caracterizou a categoria juventude de sua época como constituída por uma série de elementos que a identificam como contestatória, revolucionária, interventora, entre outras.

Alda Britto da Motta (2004) ressalta a importância da percepção acerca das relações geracionais na dinâmica política e na reprodução social, e dos seus significados na contemporaneidade, como as interconexões com outras categorias como raça, gênero e classe social, e considera, ainda, a categoria geração um elemento fundamental para a construção de políticas públicas para todas as idades. Por geração, a autora entende que esse conceito "designa um coletivo ou grupo de indivíduos que vivem em uma determinada época ou tempo social, têm aproximadamente a mesma idade e compartilham de alguma forma uma experiência ou vivência” . (MOTTA, 2004, p. 350)

O campo pesquisado aponta para outro desafio teórico-analítico acerca da categoria geração. A definição do que seria uma geração jovem tem ultrapassado os limites de uma faixa etária em seu sentido cronológico de idade preestabelecido ou de um 
período determinado para viver um estilo ou modo de vida jovem. Para exemplificar essa questão, no hip-hop pode-se reconher alguns de seus representantes que ultrapassaram os 30 anos de idade, o que até então configuraria uma idade adulta, e não mais jovem, mas que representam a juventude hip-hop.

É o que mostra o estudo "Rap, juventude e identidade" realizado por Fernanda Martins (2004), que aponta para uma flexibilidade diante da concepção de idade, que tem se apresentado relativa diante da complexidade das práticas sociais do campo da cultura. É o que pode explicar a atuação dos rappers MV Bill (RJ) e Mano Brown, da banda Racionais Mc (SP), reconhecidos enquanto estilo jovem.

O entendimento acerca dessa participação, segundo Vera Cardoso (1994), está diretamente comprometido com o problema da cidadania, especialmente quando relacionado à atuação a partir do movimento social em sua vinculação com a história e com a luta por direitos coletivos de determinados segmentos sociais. A autora destaca a importância de ultrapassar a ideia de participação delimitada apenas à luta por justiça e conscientização, diante de uma ampliação da compreensão ligada à construção da cidadania, que por sua vez, abrange as relações entre Estado e sociedade civil, e entre esfera pública e esfera privada.

Portanto, a participação é a constante luta por garantia, manutenção e ampliação de direitos. Dentre as diversas definições de participação, aqui é entendida como a forma de intervir, como um sujeito político, nas decisões políticas e públicas da sociedade, bairro, comunidade ou grupo em que se vive e interage, sejam estas em diferentes dimensões, institucionais ou autônomas.

É o que explica Ana Alice Costa (1998), tomando a participação das mulheres, atreladas às suas demandas políticas e formas de participação, quando começam a se perceber e a serem percebidas como "sujeitos políticos” capazes de intervir na história e na 
política. É interessante notar que o percurso de participação das mulheres na luta por direitos específicos tem intervido na própria ideia de igualdade, e, sobretudo, tem implicado na criação de novas formas de fazer política e no reconhecimento de novos sujeitos políticos no cenário público. ${ }^{16}$

No tocante à juventude, de acordo com Celecina Sales (2001), a participação política formal em partidos políticos e canais de representação foi bastante influenciada pelo descrédito nesses espaços, diante do contexto da crise de representação política enfrentada por países latino-americanos nas últimas décadas. O cenário de corrupção, privilégios, nepotismo e, sobretudo, o descaso da justiça em apurar e punir esses políticos tem fortalecido - não apenas, mas especialmente - entre os jovens a ideia "não gosto de política". Embora tenha ocorrido certa mudança, é corrente ouvirmos falar que as pessoas não gostam e que não querem se envolver com a política.

Além disso, há que se considerar o contexto e conjuntura latino-americana pós-ditadura militar em que o Estado foi um inimigo extremamente repressor. Mesmo no início do processo de redemocratização, até recentemente, era comum o sentimento de participação antipartido, antiestado, antisistema político. (SALES, 2001; GOHN, 2003) Entretanto, houve a criação de alternativas de organização autônomas da juventude, inclusive alternativas distintas da representação partidária, responsáveis por uma mudança na forma de participar, que pode ser compreendida através dos movimentos sociais.

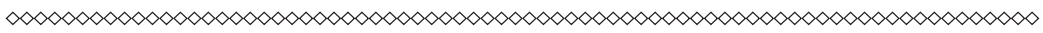

Essa afirmação pode ser brevemente contextualizada inclusive pela experiência dos movimentos feministas brasileiros e latino-americanos, que, no que seria considerada a segunda fase de alguns segmentos dos movimentos sociais, não tendo mais o Estado como inimigo, estão voltados para a relação com o Estado como aliado de suas demandas. Essa fase aponta para uma institucionalização da participação dos movimentos, garantindo uma nova forma de relacionamento entre movimento social e Estado, a exemplo do movimento de mulheres e feministas, das políticas públicas específicas para as mulheres. Entretanto, mesmo garantida no papel, há necessidade de constante luta pela sua implementação e aprimoramento, bem como pela própria efetivação e monitoramento destas. 
Há diversas interpretações para pensar a história e organização dos movimentos sociais em seus diferentes períodos, suas bandeiras e estratégias de luta. Por movimento social, Maria da Glória Gohn (2003) define um conjunto de ações sociais coletivas, de base sociopolítica e cultural, que tem por objetivo organizar de diversas formas a sociedade para reivindicar demandas e mudanças sociais. Essas ações sociais têm sido importantes na luta por cidadania, já tendo influenciado transformações políticas e sociais no decorrer da história da humanidade, a exemplo das manifestações e lutas populares.

No Brasil, a atuação dos movimentos sociais foi fundamental para a conquista de direitos registrados na Constituição de 1988 a partir dos movimentos sociais identitários, como o de mulheres, negros, homossexuais, jovens, idosos, indígenas e ecologistas. Maria Betânia Ávila (2000) contribui com esse debate ao reconhecer novos sujeitos e identidades, comprometidos pela luta por igualdade de direitos. Ela afirma que:

A pluralidade de sujeitos políticos, instituída pela ação dos movimentos sociais contemporâneos, revela que a construção da igualdade passa, justamente, pela desestruturação da ordem social, que hierarquiza as diferenças transformando-as em desigualdades. (ÁVILA, 2000, p. 6)

Essa ideia de novas identidades e estratégias de luta entre igualdade e diferença é o que justifica a posição compartilhada por Gohn e outros teóricos, que acreditam ser os anos de 1980 um período que permite embasar uma noção divisionista entre velhos e novos movimentos sociais.

Para Gonh, os que seriam chamados de velhos movimentos sociais têm uma motivação pelas lutas mais convencionais ligadas a necessidades materiais, como trabalho, moradia, alimentação. Esses eram os movimentos urbanos, camponeses, operários e de bairro e seriam identificados como movimentos reivindicatórios. 
Já os novos movimentos sociais utilizam a cultura como suporte para entender os processos de conflitos estruturantes das relações de poder na sociedade capitalista, que são compreendidos para além de termos econômicos e ideológicos. Conforme admite Maria da Glória Gohn, os novos movimentos sociais são entendidos a partir da criação de esquemas interpretativos voltados para "a cultura, a ideologia, as lutas sociais cotidianas, a solidariedade entre pessoas de um grupo ou movimento social e o processo de identidade criado”. (GOHN, 1997, p. 121) São diversos os motivos que incentivam suas mobilizações, estão entre eles: crises, desemprego, vulnerabilidade, lutas por moradia, por terra, por cultura e arte, contra a violência, entre outros. Estes eram os movimentos indígenas, étnicos, ecológicos, femininos, homossexuais e de direitos humanos. Estes seriam classificados como movimentos identitários.

A justificativa para essa divisão entre os tipos de movimentos tem base no uso das forças culturais, como se os tidos como velhos não as utilizassem e os novos as colocassem em uso em suas estratégias de luta. Entretanto, as autoras Sônia Alvarez, Evelina Dagnino e o autor Arturo Escobar (2000, p. 23) contestam essa ideia, afirmando que:

[...] os movimentos populares urbanos de favelados, de mulheres e outros, também põem em movimento forças culturais. Em suas lutas contínuas contra os projetos dominantes de construção da nação, desenvolvimento e repressão, os atores populares mobilizam-se coletivamente com base em conjuntos muito diferentes de significados e objetivos. Dessa forma, as identidades e estratégias coletivas de todos os movimentos sociais estão inevitavelmente vinculadas à cultura.

Portanto, a visão de separação dos movimentos sociais é contraposta pela explicação de Evelina Dagnino (1994), que defende que há uma luta por uma nova cidadania travada pelos movimentos sociais que se encontram sob o caráter de estratégia política. 
Entretanto, a demanda por uma nova cidadania está reservada para grupos que reivindicam o direito a ter direitos. Esses direitos estão vinculados em especial ao espaço urbano, constituindo uma demanda de direito à cidade por ambos os movimentos, sejam os movimentos urbanos e também identitários como os movimentos negros, de mulheres, LGBTT, e outros.

Objetivamente, esses grupos e movimentos pressionam uma transformação social pela construção de uma nova cultura democrática e, portanto, uma nova cultura de cidadania divergente da ordem hegemônica. Para tanto, a estratégia política utilizada por esses grupos e movimentos é contínua em sua construção, entendida como um processo embasado por lutas práticas e concretas, atualizadas diante da dinâmica dos conflitos sociais e ligadas ao seu momento histórico. (DAGNINO, 1994)

Apreende-se que a questão central deste debate sobre a existência ou não de uma divisão entre velhos e novos movimentos sociais não se sustenta. O que realmente está em jogo é o interesse acerca do que motiva a participação desses sujeitos. Concordando com a revisão sobre os movimentos sociais, Eder Sader (1988) acredita que o que mobiliza as pessoas são muitas questões definidas em volta da cultura como um aspecto fundamental. Essa ideia orientou sua pesquisa sobre as novas configurações sociais assumidas pelos trabalhadores da Grande São Paulo no curso da década de 1970, quando os movimentos sociais criaram novas formas e espaços políticos para tratar de questões em volta de releituras de temas presentes nas suas experiências cotidianas.

$\mathrm{O}$ autor aponta que as mudanças contestadas pelos movimentos podem ser resultado de um efeito retardado da repressão do regime ditatorial, que fez com que a sociedade civil surgisse expondo uma crise de representação e referenciais políticos, e reconhecesse o político para além do Estado e dos partidos. Ele justifica esse processo, “à medida que as modalidades da produção 
capitalística invadem todos os poros da sociedade, provocam também uma inédita politização no social e, com isso, um descentramento do político". (SADER, 1988, p. 54) É o “novo” no sentido de quebra com um modelo dominante que permite a criação de uma nova forma de fazer política que altera estratégias de ação e redefine valores. Nesse contexto, esses movimentos experimentavam uma nova socialização em que se desenvolviam relações de solidariedade entre os novos sujeitos políticos.

Outra colaboração relevante a esse debate vem de Ana Maria Doimo (1995), que aponta nova contribuição para as reflexões sobre a teoria dos novos movimentos sociais, especialmente em relação à abertura de um expressivo campo ético-político como reflexo do processo político brasileiro. Entretanto, diante de sua vasta experiência em contato com diversos movimentos sociais, e, em especial, o Movimento de Luta contra o Desemprego (MCD) (1982 a 1985), ela afirma que "tornava-se até constrangedor ter de dizer que ali, no MCD, não se encontrava um exemplo desses novos sujeitos políticos, destinados a tal ruptura, mesmo porque a realidade era cruel”. (DOIMO, 1995, p. 29) Esse contexto se colocava como desafiador aos movimentos diante da proposta de contraponto a uma cultura política dominante, sendo compartilhado por diferentes experiências de mobilizações, que lidam com questões em torno da ética na relação com Estado, institucionalidades, partidos políticos, lideranças e outros movimentos; e da própria ideia de luta imediata, fragmentação de grupos e bandeiras, e da possibilidade de um esgotamento da luta após a conquista de direitos.

Assim, a discussão em torno desta perspectiva sobre os movimentos sociais perdeu espaço para questões mais relevantes, como, por exemplo, as dimensões que compõem os movimentos e direcionam suas ações. Nesse sentido, Evelina Dagnino (1994) defende que todos os movimentos atuam sob estratégias democráticas 
direcionadas pelas dimensões da política e da cultura, estando localizados em seu específico tempo, espaço e contexto social.

Com isso, a dimensão cultural abarca os aspectos subjetivos em que atua o diálogo entre as múltiplas identidades constituintes dos novos sujeitos e suas necessidades de uma nova cidadania, que dê conta dessa diversidade. Contudo, essa demanda é um processo de aprendizado que interfere não apenas nas políticas e institucionalidades do Estado, mas tem seu foco nas relações sociais em todos os seus níveis. Especialmente no que tange à dinâmica social da sociedade civil para além do Estado e da política formalizada, em que a ordem defendida é o direito de participar e de exercer o direito de cidadã ou cidadão.

Nesse sentido, a atuação dos movimentos sociais inicialmente é caracterizada por uma prática de uma política criada pelos/para os grupos ou organizações autônomos, representantes da sociedade civil. Essa prática pode passar por um processo de institucionalização em relação a uma nova forma de se relacionar com o Estado - incidindo nas políticas públicas -, instituições, e outros grupos e movimentos, e também pode ser identificada como uma política cultural do movimento social que terá maior atenção em breve.

As autoras Sônia Alvarez, Evelina Dagnino e Arturo Escobar (2000, p. 21) concordam que "os movimentos sociais são uma arena crucial para a compreensão de como esse entrelaçamento, talvez precário, mais vital, do cultural e do político ocorre na prática". A referência da experiência dos movimentos sociais visibiliza o caráter ativo e relacional da cultura e da política que, reunidas em uma política cultural, atuam de forma a confrontar o que seria a cultura política hegemônica na sociedade.

Portanto, se os movimentos sociais pretendem modificar o poder social e se a cultura política abrange campos institucionalizados para a negociação do poder, então os movimentos sociais necessariamente enfrentam a questão da cultura política. 
Em muitos casos, os movimentos sociais não exigem inclusão ou mesmo a tomada de poder, mas antes buscam interferir e reconfigurar a cultura política dominante. Portanto, eles atuam de forma a modificar a cultura política vigente na sociedade.

Entretanto, a cultura política pauta a questão sobre o que conta como político, o que implica também em quem é ou quem são os sujeitos políticos. Para tanto, esse debate abrange diversas perspectivas. Assim, Norberto Bobbio (2000) compreende a cultura política como um conjunto de elementos que constituem determinada sociedade, no qual se incluem ideias e crenças, normas e tradições e instituições políticas. Segundo Maria da Glória Gohn (2005), há uma ligação entre os espaços do formal e do informal ao considerar a cultura política como o resultado do processo de educação vinculado à cultura, ao passado e ao cotidiano. Ambos os autores contribuem para a discussão, entretanto, não aprofundam a relação entre as práticas dos movimentos sociais e cultura política.

Já Evelina Dagnino, Sonia Alvarez e Antonio Escobar (2000) defendem que o conceito de cultura política entrelaça cultura e política, redefinindo os limites desta; torna capaz de reconhecer as relações de poder embutidas na cultura e que são responsáveis por dar significado às práticas sociais. Assim, essas autoras definem os conceitos de cultura e política de forma separada.

Para elas, cultura é

entendida como concepção do mundo, como conjunto de significados que integram práticas sociais, não pode ser entendida adequadamente sem a consideração das relações de poder embutidas nessas práticas. (DAGNINO; ALVAREZ; ESCOBAR, 2000, p. 17)

Política é algo mais que um conjunto de atividades específicas (votar, fazer campanha ou lobby), que ocorrem em espaços institucionais claramente delimitados, tais como parlamentos e 
partidos, ela deve ser vista como abrangendo também lutas de poder realizadas em uma ampla gama de espaços culturalmente definidos como privados, sociais, econômicos, culturais e assim por diante. (DAGNINO, ALVAREZ; ESCOBAR, 2000, p. 29)

Enfim, esse laço constitutivo também significa as relações de poder, que não podem ser entendidas sem o reconhecimento do caráter "cultural ativo" para a compreensão de suas expressões e significados. Portanto, a cultura e a política estão intrinsecamente associadas e mutuamente se influenciam e se constituem. Assim explicam Dagnino, Alvarez e Escobar (2000, p. 24-25):

A cultura é política porque os significados são constitutivos dos processos que, implícita ou explicitamente, buscam redefinir o poder social. Isto é, quando apresentam concepções alternativas de mulher, natureza, raça, economia, democracia ou cidadania, que desestabilizam os significados culturais dominantes, os movimentos põem em ação uma política cultural.

Assim, a prática dos movimentos sociais pode ser compreendida por política cultural, que se supõe resultado de concepções e visões de mundo de grupos minoritários que se relacionam com uma determinada ordem cultural dominante. Em diálogo com o campo interdisciplinar estão alguns estudiosos que se dedicaram a pensar sobre esse assunto; estão presentes cientistas políticas(os) e antropólogas(os) em especial, interessadas em entender o que seriam realmente as novas práticas políticas e as propostas de "novas culturas políticas", mais especificamente construídas a partir das experiências dos movimentos sociais.

Vale ressaltar que essas práticas dos movimentos são expressas de várias formas, a exemplo dos debates políticos que criam ou dão novos significados às interpretações culturais dominantes da política e que desafiam sujeitos e práticas políticas estabelecidas como hegemônicas. Para tanto, Dagnino, Alvarez e Escobar (2000, p. 24) defendem 
as contestações culturais não como meros 'subprodutos' da luta política, mas ao contrário, são constitutivas dos esforços dos movimentos sociais para redefinir o sentido e os limites do próprio sistema político.

A importância está em participar e contribuir com o debate e decisões públicas que interferem na vida da população e das diferentes gerações. Essa forma de participar é nova, pois está aberta para inovações e reconfigurações, com novos espaços, sujeitos, meios e instrumentos. É o que explica Sader (1988, p. 32-33):

Pequenos atos, que até então seriam considerados insignificantes ou reiteração de uma impotência, começam a receber novas conotações. Manifestações incapazes de incidir eficazmente sobre a institucionalidade estatal - antes interpretadas como sinal de imaturidade política - começam a ser valorizadas como expressão de resistência, de autonomia e criatividade.

Adentrando no campo desta pesquisa, o "novo" espaço criado pelo hip-hop enquanto expressão artística e cultural entrou na cena dos movimentos políticos. O Hip-hop foi considerado um dos fenômenos mais importantes no mundo atual, e chegou até a ser classificado por Maria da Glória Gohn (2004), em sua interpretação teórica, como inserido no rol dos novos movimentos sociais, justificado por este integrar três perspectivas: 1) Possibilita a inclusão de novos atores e atrizes no contexto de luta política, implicando na construção de identidade; 2) Utiliza a cultura como ferramenta política na luta por direitos e cidadania; e 3) Está vinculado ao campo internacional e à esfera tecnológica em sua história.

Para a estudiosa Priscila Matsunaga (2006. p. 12), o Hip-hop é "o novo dos novos movimentos sociais" porque

[...] promove a construção de atores/sujeitos que reivindicam, num primeiro momento, um reconhecimento de sua existência; 
reivindicam direitos e garantias sociais e se constituem como um grupo que atua politicamente utilizando a arte.

À ideia de novo está vinculada a contextualização histórica do hip-hop, em seu percurso de formação e expansão pelo mundo, bem como através das experiências de suas diferentes gerações e espacialidades que o configuram como movimento social.

Por hip-hop entende-se a composição de manifestações que se expressam através das artes de matrizes culturais africanas, caribenhas e americanas, atreladas a aspectos modernos - entre eles, a própria união de diversas matrizes culturais, a reconstrução de identidades na diáspora - e tecnológicos. Sua origem remonta aos anos 1970, quando jovens afroestadunidenses e imigrantes caribenhos e latinos residentes do Bronx, bairro periférico de Nova Iorque (EUA), deram forma ao Hip-hop e aos seus elementos básicos: break, rap, grafite e DJ (SANTOS; SUNEGA, 2009), como já referido anteriormente.

Todas essas artes expressas pelo hip-hop e que configuram os elementos com linguagem desta cultura juvenil não se restringem apenas ao âmbito estético e musical, também produzem discursos para a luta política, tendo em sua essência a educação - informal, produzida na rua em diversos espaços urbanos e situações do cotidiano - estimulada e embasada na atuação da juventude. Essa característica pode ser compreendida a partir do conhecimento da constituição do hip-hop e seus elementos, o qual acontece nos Estados Unidos inserido num cenário político pós-movimento por direitos civis, ocorrido durante os anos de 1930 e 1950.

A luta pelos direitos civis influencia e fornece a primeira geração hip-hop nos Estados Unidos, que, posteriormente, será também referida às próximas gerações em outros países, em distintos 
aspectos. Em relação às lideranças, ${ }^{17}$ destacam-se personalidades, a exemplo de Rose Parks, ${ }^{18}$ Martin Luther King, ${ }^{19}$ Malcolm $\mathrm{X}^{20}$ e Angela Davis ${ }^{21}$ e as formas de organização de grupos políticos como os Panteras negras. Também são importantes as diversas estratégias de participação política como boicotes de ônibus, passeatas, produção de jornais e outros.

O surgimento do Hip-hop foi marcado pela reunião de seus elementos que já existiam em separado, como o break e o grafite, conhecidos como os velhos elementos (the old elements). Inicialmente, esses elementos foram utilizados como uma alternativa de lazer para a juventude negra e latina dos bairros da periferia, que viviam sob uma realidade de violência entre gangues, as quais disputavam espaços, ideologias e tinham um intenso envolvimento com o tráfico de drogas. É neste contexto de embate social que o hip-hop se transforma em uma alternativa política.

A juventude hip-hop - conhecida nos Estados Unidos como hip-hop generation ${ }^{22}$ e/ou post-soul - reconhece questões em

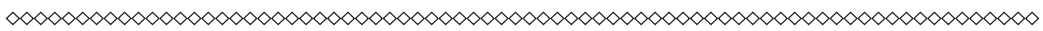

17 Personalidades atuantes durante o movimento por direitos civis nos Estados Unidos que se destacaram como lideranças e representantes da população negra, que lutavam por direitos iguais e combate ao racismo, e tornaram-se referencias dessa luta por todo o mundo e, sobretudo, para as gerações seguintes.

18 Rose Parks foi presa e multada por ter se recusado a ceder seu lugar no ônibus a um branco, contrariando o que estava previsto na lei de segregação racial em seu país. Seu ato deu início ao que foi chamado de "Boicote de ônibus de Montgomery" (Alabama). (ALVES, 2011)

19 Martin Luther King Jr., pastor da igreja batista na Geórgia, tinha sua militância inspirado no líder indiano Mahatma Gandhi, e conhecido especialmente por seu discurso na Marcha de Washingthon, em 1963, intitulado I have a dream, um sonho de que o respeito às diferenças fosse alcançado em seu país e no mundo. Luther King liderou, juntamente com outras pessoas, os boicotes aos ônibus e às leis de segregação racial, que duraram 381 dias, tendo como resultado, entre outros, a quebra de inúmeras empresas de transporte. (ALVES, 2011)

20 Malcolm X, como era chamado Al HajjMalik Al-Habazz, importante referência da luta pelos direitos da população negra nos Estados Unidos.

21 Angela Davis, professora e escritora, importante militante do movimento Black Power, candidata em duas eleições presidenciais pelo Partido nos Estados Unidos durante os anos 1980.

22 Termo dado para identificar o segmento da juventude negra estadunidense nascida entre os anos de 1960 e 1980, que compartilhava um sistema de valores herdado pela geração anterior, cunhado nos anos de 1990, por Bakari Litwana, editor da The Source: Magazine of Hip Hop, Music Culture and Politics. Posteriormente, essa juventude foi chamada por Mark Anthony Neal de post-soul, pois descrevia as experiências culturais, sociais e políticas da população negra estadunidense desde o final dos movimentos por direitos civis e Black Power. (COLLINS, 2006) 
comum entre pessoas e bairros negros e latinos a partir da cultura hip-hop como parte de um fenômeno global. Segundo Collins (2006), essa juventude afro-estadunidense alcançou visibilidade da mídia para aprofundar os debates em torno das questões de gênero, raça, nacionalidade, idade e sexualidade, refletindo as contradições do novo racismo, vivenciando o contexto de explícitas leis de segregação racial e o ideal de oportunidades da "América" livre.

Essa juventude negra e latina estadunidense passou a se organizar e promover ações de socialização de grupos pela não violência de gangues, iniciando batalhas artísticas de dança e de rimas improvisadas. É nesse contexto político que surge a Zulu Nation, a primeira organização do movimento, responsável por promover o hip-hop e seus elementos em âmbito internacional, tendo como lema a conscientização da juventude através da educação (informal e do cotidiano urbano-artístico). Essa organização pode ser encontrada em praticamente todos os continentes, e foi responsável por politizar a cultura hip-hop e tratá-la como um instrumento de luta política. Dessa forma, ela é reconhecida pelos segmentos do movimento social hip-hop baiano, tendo representantes em Salvador.

O Hip-hop é identificado por Stuart Hall (2003) e Paul Gilroy (2001) - embasados pelos estudos descoloniais ${ }^{23}$ - como uma das expressões culturais da diáspora africana. Com o conceito de diáspora, os autores pretendem abarcar um novo momento de sociabilidade de uma população ou de um grupo étnico marcado por processos de deslocamento, fuga, exílio, migração forçada na reconstituição da identidade, acreditando que esse conceito pode ser usado na substituição do termo "raça". Ele permite também explicar a conexão entre hip-hop, juventude negra e vivência em

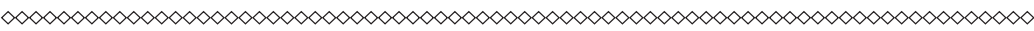

23 Por estudos descoloniais entendo os estudos embasados na desconstrução de um modelo hierarquizado e subalterno de produção de conhecimento, tratando de temas atuais como identidades, migrações, território, diáspora e outros. 
bairros periféricos caracterizados pelas desigualdades sociais e identificados pelas categorias de raça, de classe, de geração e de espaço (no caso, urbano e periférico).

O termo diáspora auxilia na compreensão do contexto social no qual o Hip-hop surgiu e se desenvolveu nas décadas seguintes nos Estados Unidos e também no Brasil, como em outros países americanos, caribenhos, europeus e até africanos em diferentes configurações. O surgimento do Hip-hop nos Estados Unidos e no Brasil compartilha condição de uma alternativa de lazer, divertimento e mecanismos de contenção e substituição da violência física das brigas de gangues pelas "batalhas" artísticas em seu primeiro momento. Posteriormente, ele tornou-se movimento político munido das expressões artísticas de seus elementos, como apresentado anteriormente.

No decorrer da primeira geração do movimento baiano, foi extremamente rica a mudança de participação e organização social da juventude negra baiana do movimento Hip-hop, voltada inicialmente para preocupações com sua comunidade e o entendimento sobre questões de sua identidade e história, e, posteriormente, para a ampliação de seu campo de ação na cidade e o envolvimento com a discussão acerca das políticas públicas comprometidas com o desenvolvimento da comunidade negra.

Como exemplo dos temas envolvendo essas políticas estão: a Lei $n^{\circ}$ 10.639/ 03 de inclusão da história e cultura da África e afro-brasileiras nos currículos escolares; atenção à saúde da população negra e, em especial, à anemia falciforme; ações afirmativas e cotas no ensino superior; regulamentação do trabalho doméstico, combate à violência contra a mulher, dentre outras. Ações que se desenvolvem de forma articulada com outros segmentos, que atuam a partir do diálogo "com o poder público local, promovendo interação entre as demais cidades brasileiras, e realizando 
encontros nordestinos e de gênero, com um grau de organização muito próprio". (OLIVEIRA, 2007, p. 66)

As artes do hip-hop tornam-se um instrumento que expõe a condição dos/das jovens e da sua reivindicação de direitos junto ao poder público. (MATSUNAGA, 2008) A juventude hip-hop baiana realiza, através dos elementos artísticos do movimento, denúncias das desigualdades sociais vivenciadas pela população negra, jovem e pobre das periferias soteropolitanas. São exemplos as intervenções públicas na campanha "Hip-hop pelas cotas", feitas na reitoria da Universidade Federal da Bahia (UFBA), com a apresentação de break, de bandas de rap, de performances de uma djeia ${ }^{24}$ - praticamente a única djeia do estilo hip-hop - ${ }^{25}$ e de DJs e exposições de grafites, além da promoção das mesas de debates com integrantes do movimento e convidados representantes de outros segmentos do movimento negro. Esse evento está registrado no documentário produzido pela TVUFBA, além da própria universidade ter produzido um single com a música "Quadro negro” da banda Simples Rap'ortagem. (OLIVEIRA, 2007)

Na Bahia, o surgimento do Hip-hop na década de 1990 se deu num período em que a participação das mulheres no movimento ganhou visibilidade no cenário brasileiro através de intervenções de algumas hip hoppers icônicas, que ajudaram a constituir grupos e ações do Hip-hop no país. Essa década teve um importante significado em relação à participação e identidade das mulheres negras, segundo Maria Aparecida da Silva (1995, p. 516), pois “[...] o surgimento da organização do movimento de mulheres negras no Brasil é concomitante ao surgimento das primeiras rappers”.

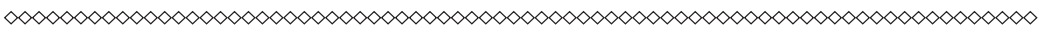

24 Djeia é um termo do campo, utilizado pelas mulheres do próprio movimento para nomear aquelas que atuam com o elemento musical DJ.

25 Sendo mais frequente encontrarmos Djeias de estilos de músicas eletrônicas, a exemplo do estilo techno.
} 
É nesse contexto que as jovens baianas se inserem nos espaços do movimento Hip-hop em Salvador, sob a compreensão de que esse movimento se constitui num dos segmentos do movimento negro baiano em sua primeira geração. Afinal, o que impulsiona as jovens negras do hip-hop a se mobilizarem?

Essa resposta tem lugar nas discussões sobre os temas pautados por integrantes do Hip-hop e surgem a partir das experiências do próprio cotidiano dessas jovens, interferindo nas pautas do movimento. Sobre a diferença entre as experiências de homens e de mulheres, a rapper baiana Mara Asantewaa pontua:

Não porque exista um papel para um ou para outro, mas é porque a realidade de uma mulher é diferente da realidade de um homem, principalmente quando é o movimento social, inclusive quando é o hip-hop. (SOUZA; SANTOS, [2009])

A fala da rapper aponta um caminho a ser perseguido para a compreensão dos modelos de feminilidade e de masculinidade e suas convenções de gênero no movimento e na sociedade, foco desta investigação.

\section{Questões metodológicas}

Esta pesquisa qualitativa contou com o trabalho de campo dividido em dois momentos. O primeiro momento ocorreu durante a primeira fase da pesquisa, em 2008, em vias ao trabalho monográfico do bacharelado em Ciência Política, com a realização de entrevistas e observação participante. Esse material serviu de base para este livro, já que no trabalho anterior não me foi possível explorar todo o material coletado.

No segundo momento, ocorreu o retorno ao campo de março a agosto de 2010, ao revisitá-lo com um olhar sob uma forma interdisciplinar e interessada na etnografia do cenário pesquisado. 
Assim como Angela Maria de Souza (2009), que desenvolveu seu trabalho sobre o movimento Hip-hop em Florianópolis em dois momentos distintos, também tive a oportunidade de revisitar o campo em Freire (2010).

Durante o intervalo entre os períodos dos trabalhos de campo, mantive contato com as interlocutoras e informantes, além de eventuais encontros em atividades outras pela cidade. Nessas oportunidades, trocamos informações, tiramos dúvidas sobre determinadas questões e eu as atualizava do andamento do trabalho e/ou escrita do "nosso livro", como algumas delas se referiam. ${ }^{26}$

Em se tratando de uma pesquisa de caráter feminista e interdisciplinar, faz-se relevante refletir sobre as questões metodológicas que orientaram essa investigação. Primeiro, com respeito à mudança de orientação metodológica em meio ao processo de escrita, entre a ciência política e a antropologia. Assim, a análise que se apresentará tem esse duplo pertencimento.

Outro aspecto que importa destacar está direcionado à perspectiva feminista que embasa esta pesquisa. Essa perspectiva se traduz ao analisar as relações de gênero, entendo-as como relações de poder, que são vivenciadas entre homens e mulheres na sociedade, a qual, segundo Betânia Ávila (2007), é capaz de perceber a mulher como "sujeito político" do processo de transformação social, interferindo nos processos sociais. Essa concepção permite a possibilidade do rompimento com a perspectiva naturalista de vitimização e fragilização das mulheres.

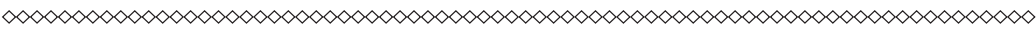

26 Após finalizar meu trabalho de campo, durante os meses de outubro e novembro de 2010, em meio à experiência do intercâmbio na Universidade Federal de Santa Catarina (UFSC), em Florianópolis, ocorreu a oportunidade de conhecer o campo de trabalho estudado por Angela Souza (2009) na cidade - já que a pesquisadora também investigou o hip-hop em Lisboa. Nessa experiência, tive contato com um segmento do movimento Hip-hop: o hip-hop gospel. Além de conhecer expressões de seus trabalhos quando visitei uma igreja evangélica, assisti a uma apresentação de uma banda de rap e à exibição de um dos seus videoclipes. A igreja referida garantia equipamentos e material de qualidade para as produções. Segundo Angela, os hip hoppers gospéis colocavam que adentravam hoje em lugares que nem polícia nem pastores entravam. Também nessa oportunidade marcamos com uma rapper que não pertencia a esse segmento gospel do Hip-hop, mas infelizmente ela não compareceu ao encontro marcado. 
Outra premissa estabelecida pela perspectiva feminista sobre a qual se apoia este estudo é embasada pela experiência de buscar novos referenciais teóricos para analisar o comportamento feminino. (BRITO, 2001) Além disso, a direção foi a um relativamente novo contato com o campo da antropologia e da etnografia feminista. (HARAWAY, 1995; SARDENBERG, 1998; BONETTI, 2007)

A escolha em ressaltar a produção de um conhecimento situado (HARAWAY, 1995) está embasada pela pesquisa que se aproxima da etnografia, sem que haja a pretensão ao olhar exatamente de uma antropóloga, inclusive reconhecendo a base da ciência política, mas disposta a refletir acerca das ubiquidades (BARROS, 2007) na aproximação da relação e da identidade com interlocutoras de sua pesquisa. Por isso, esta pesquisa pretende passear pelo campo da antropologia e de uma produção de cunho etnográfico.

Ao pensar os desafios do campo, já nos primeiros contatos com o movimento Hip-hop, foi percebido que havia algumas questões que, de certa forma, fechavam ou limitavam o contato das pessoas e grupos com pesquisadoras. Havia um receio por parte do movimento social em disponibilizar informações ou mesmo abrir seu espaço para pessoas de fora. Para compreender esse campo, primordialmente, fazia-se necessário "olhar o mundo do ponto de vista dos nativos" (GEERTZ, 1997), embora não estivesse estabelecida a pretensão de realizar uma etnografia, mas de utilizar estratégias etnográficas para compreender aquele cenário, e das suas principais questões e constrangimentos. Postura defendida por Clifford Geertz (1997) - em seu estudo sobre os javaneses, balineses e marroquinos - para que o olhar da pesquisadora não sobressaia em relação ao grupo pesquisado, ou vice-versa, para que não haja uma hierarquia entre eles, e se possa apreender os sentidos e símbolos do cenário que os rodeiam, em que se inserem sentimentos, expectativas e ponto de vista. Uma lição para nos abrimos para a compreensão do campo em questão. 
Nesse sentido, essas "restrições" em torno das pesquisas que continuavam acontecendo - seriam uma espécie de defesa do Movimento ao uso da sua imagem e ao acesso das suas informações por parte de pesquisadores. Essa ideia de preservação do próprio movimento é compartilhada por muitos dos que podemos chamar de movimentos sociais, grupos culturais e religiosos, bastante procurados para fins de pesquisa por estudiosos locais e internacionais, justificados muitas vezes devido à falta de retorno desses trabalhos de pesquisa para seus pesquisados. Para tanto, o movimento Hip-hop cria alternativas possíveis para, como é chamado por eles mesmos, uma relação de feedback - relações de trocas e parcerias entre o movimento e pesquisadoras(es) do tema. Essa oportunidade cria vínculos entre a pesquisa, a pesquisadora e as(os) pesquisadas(os).

No que seria o primeiro momento desta pesquisa, durante a graduação, desenvolveu-se ações importantes, tendo a relevância da experiência do curso de inglês "I have a Dream: English for Black Empowerment" ${ }^{27}$ para o movimento Hip-hop e outros movimentos sociais, no ano de 2007, no Centro de Estudos AfroOrientais (CEAO)/28 UFBA. (FREIRE, 2010) Essa experiência foi extremamente rica em vários sentidos: ampliação do contato com integrantes do movimento; afirmação da posição como pesquisadora do tema, e a criação de uma oportunidade de troca com o movimento a partir de suas demandas principais: educação e ampliação de estratégias de oportunidade de trabalho para a

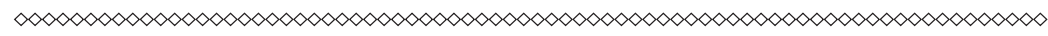

270 curso consistiu numa parceria do Núcleo de Mulheres da Rede Aiyê Hip-Hop, um dos segmentos do movimento Hip-hop em Salvador, reunindo diversas posses, e o grupo We are problematic! English for Black Empowerment - formado pelo grupo de estudantes de Ciências Sociais/ UFBA, integrantes do programa de intercâmbio "Raça, Desigualdades e Desenvolvimento: uma comparação Brasil e Estados Unidos" (UFBA e Vanderbilt University), autoras do material didático e responsáveis por ministrarem as aulas. Participei desse grupo e do projeto como propositora.

28 Centro de Estudos Afro-Orientais (CEAO) é um órgão suplementar vinculado à Faculdade de Filosofia e Ciências Humanas (FFCH) da Universidade Federal da Bahia (UFBA). Esse centro abriga projetos de pesquisa e atividades abertas à comunidade envolvendo temas da história e cultura afro-brasileiras. Disponível em: <http://www.ceao.ufba.br/2007/apresentacao.php>. 
juventude negra e da periferia - no caso, aprender inglês, seja para os vestibulares ou para o mercado de trabalho. A iniciativa reuniu diferentes grupos de jovens, sendo bem-vista pelo movimento e organizações. O curso não teve continuação por falta de recursos para sua gerência.

Refletindo sobre situações da pesquisa durante uma conversa com a rapper Mara Assantawaa, esta colocou que durante certo tempo decidiu "não mais conversar com pesquisadores" diante de complicações entre a relação pesquisador-pesquisados. Um dos casos relatados se refere ao conhecimento, durante o trabalho de campo, na descoberta de fotos dos grupos de hip-hop baianos em publicações como revistas e pesquisas europeias e estadunidenses, sem que esses grupos sequer tenham ciência de quem os registrou, sem autorização prévia ou sem retorno para o grupo.

Devido a uma aproximação e participação ${ }^{29} \mathrm{em}$ atividades do Movimento, havia um receio de dois lados - por parte do movimento e por parte da academia - acerca de uma possível confusão em relação ao meu pertencimento àquele movimento e ao distanciamento necessário para a realização da pesquisa, justificado pela relação de parceria com os grupos pesquisados. Essa era uma preocupação pessoal, e sempre que era oportuno situava o lugar e o objetivo da presença nesses espaços como pesquisadora. ${ }^{30}$

29 Em outras oportunidades, participei como palestrante, apoio administrativo, fotógrafa e filmaker em eventos e ações do movimento.

Duas oportunidades que reconheceram minha posição com relação a este trabalho foram dois importantes convites para apresentação da pesquisa. 0 primeiro foi para participar de uma mesa de debate no Seminário Coisa de Menina (2010), pelo movimento de mulheres do hip-hop, referente ao trabalho da graduação, e o segundo foi o convite para participar da abertura da calourada do curso de graduação em Gênero e Diversidade (2011), FFCH/UFBA, pelas professoras universitárias. Nessa segunda experiência, fui convidada pelas professoras do curso, vinculadas ao Núcleo de Estudos Interdisciplinares sobre a Mulher (NEIM), o qual é responsável pelo curso de graduação em Gênero e diversidade (bacharelado), e pelo Programa de Pós-graduação em Estudos Interdisciplinares sobre Gênero, Mulheres e Feminismo (PPGNEIM), ao qual está ligada esta pesquisa. 0 objetivo da apresentação, a partir da realização desta pesquisa, foi de ligaçãa entre a graduação e a pós-graduação, e tive a oportunidade de convidar duas rappers - Mara Assantawaa e Jamile Santana - para apresentarem seus respectivos trabalhos sobre o tema das mulheres. As atividades foram planejadas juntamente com as professoras do colegiado do NEIM, 
Esse foi um desafio que esteve presente, em especial, no primeiro momento da pesquisa (graduação), e que foi amadurecido na pós-graduação.

O contato com as jovens foi extremamente importante para garantir a compreensão acerca do universo hip-hop, de suas linguagens e dos símbolos utilizados por suas/seus integrantes, especialmente em torno das gírias, roupas, penteados e outros, de forma a identificar o conhecimento situado nesse universo. Durante o decorrer da pesquisa, foi mantido o contato com as mulheres do hip-hop em diferentes oportunidades, como reuniões dos grupos (quando possível), atividades públicas e interações com outros movimentos e de pautas gerais em que o movimento Hip-hop estivesse presente, no intuito de perceber o modo de atuação e como se dão as relações sociais internas e externas.

Assumindo o método qualitativo de pesquisa, sob o olhar da epistemologia feminista, trabalho com entrevista em profundidade do tipo semiestruturada com um único correspondente. (GASKELL, 2002) Para tanto, as técnicas de investigação utilizadas foram: a realização de entrevistas com roteiro semiestruturado junto às hip hoppers, e observação participante oriunda da convivência junto ao grupo estudado, com o suporte da confecção de diário de campo, que permitiu a construção de um cunho etnográfico para este trabalho, além da coleta de material audiovisual e impresso sobre os grupos e atividades, CDs, DVDs, materiais de jornais e revistas, fanzines, material fotográfico e outros.

A observação participante desenvolveu-se no processo de convivência junto às hip hoppers dentro de uma intensa agenda de mobilizações, sendo importante para perceber como ocorrem as relações entre as pessoas do grupo pesquisado e o próprio ambiente em que atuam. Vale destacar que inúmeras vezes foi

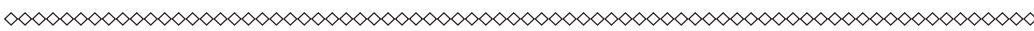
em especial, Professora Sílvia Aquino, a partir da construção de acordos e trocas entre o Núcleo e as hip hoppers. 
explicado o motivo que justificava esta presença em campo. Inicialmente, explicava de forma mais detalhada e descrevia a proposta do projeto. Depois, apenas dava informação sobre a realização de uma pesquisa sobre um suposto "Hip- hop feminista", o que já prendia a atenção e curiosidade das e dos hip hoppers, os quais explicavam uns aos outros o meu trabalho de escrita do livro sobre as mulheres do Movimento. Durante a inserção em campo, a postura assumida como pesquisadora era de estar aberta para perguntas dos indivíduos e dos grupos sobre esse trabalho, especialmente às lideranças do movimento, bem como em pedir seu o apoio e colaboração, como parceiras interlocutoras/es, para a realização desta pesquisa.

Foi fundamental o contato direto com indivíduos-chave do grupo estudado para garantir a transparência do trabalho e o trânsito no ambiente em questão, especialmente para as pessoas que lideravam ou estavam à frente das articulações, pois estas poderiam repassar meu objetivo ali, por outras vias, e internamente. Além disso, em diversos momentos ocorreu o contato com diferentes informantes-chave e colaboradoras para a pesquisa, com diálogo aberto e muito valioso sobre questões delicadas do trabalho de campo.

Diante de tantas articulações provocadas pelas perguntas à pesquisa, foi apreendido as observações compartilhadas por Willian Whyte em sua pesquisa com os Norton, em Corneville, em 1937. Ele relata que na observação pôde ter, "sentado e ouvindo, as respostas às perguntas que nem mesmo teria tido a ideia de fazer se colhesse minhas informações apenas por entrevistas” (2005, p. 304). Imersa no ambiente de estudo, o esforço em observar as hip hoppers, que mesmo diante do compartilhamento de interesses e inquietações, embora de perspectivas distintas, lembravam-me frequentemente sobre nossas distinções de lugar de fala. Observações essas que produziram a confecção do diário de campo como técnica para registro 
sobre o que se encontrou no campo estudado - a cidade de Salvador -, em seus percursos, lugares, encontros, shows, personalidades, seminários ou/e questões que envolviam o hip-hop. Além disso, nas notas sobre o campo também constam observações das entrevistas realizadas de conversas informais no debate e elucidação de dúvidas com as informantes.

As entrevistas realizadas junto às hip hoppers foram auxiliadas pelo roteiro semiestruturado, sendo que algumas delas foram reconectatadas (algumas vezes) para elucidar dúvidas sobre tópicos do roteiro. A seleção da amostra de entrevistadas ocorreu sob os seguintes critérios de escolha: 1) Ser militante do movimento hip-hop; 2) Ter participação (anterior ou atual) em coletivo de mulheres ou em grupos mistos; 3) Ser independente ou mesmo parceira do movimento; e 4) Ter envolvimento com os elementos do hip-hop desenvolvendo técnicas para fomentá-lo e/ou ações para produzi-lo.

A seleção das entrevistadas ocorreu através do levantamento e identificação das mulheres no Movimento, sendo reconhecidas durante o trabalho de campo e/ou citadas e indicadas pelas próprias entrevistadas. O objetivo foi criar uma rede de contatos que permitisse um contato prévio das entrevistadas com a pesquisa, a fim de minimizar o efeito da "desejabilidade social”, traduzido pela situação em que a pessoa entrevistada responde com opiniões socialmente desejáveis. (BARRETO, 2008) Nessa seleção do grupo de entrevistadas foi priorizada a heterogeneidade interna das participantes, no tocante à escolaridade, orientação sexual, bairro, atuação, posse, entre outras variantes.

O contato com as jovens aconteceu previamente e a realização de entrevistas aconteceu inicialmente com caráter de teste do instrumento - roteiro de entrevista - para aprimoração do mesmo e como levantamento preliminar dos dados. Foram totalizadas oito entrevistas, realizadas no circuito do centro da cidade, em 
atividades do movimento. Após as entrevistas serem devidamente transcritas, foi construído um banco de dados, e, posteriormente, ocorreu o processo de construção das categorias seguida da análise de seus conteúdos e interpretações possíveis.

Todas as entrevistas contam com a devida autorização das entrevistadas, sob uma preocupação ética, respeitando suas escolhas quanto à forma de divulgação de seu nome neste trabalho. Para elas, foi apresentado um documento da pesquisa que inclui informações referentes ao objetivo acadêmico e social deste trabalho para o seu conhecimento.

\section{As interlocutoras desta pesquisa}

Abaixo temos alguns dados acerca das entrevistadas que optaram assumir sua própria identidade e nomes reais.

Carla Cristina de Jesus Santos ou Kaia na Paz (nome artístico), rapper e b-girl, 23 anos, negra, soteropolitana, solteira, mora com pai, mãe e irmã no bairro Vila Canária, tendo renda familiar de um a três salários mínimos, cursa Pedagogia na UFBA e é cotista, trabalha com projetos educacionais e compõe a banda de rap Munegrale.

Simone Gonçalves Santos, rapper e b-girl Negramone, 25 anos, negra, soteropolitana, lésbica/casada, mora com companheira no centro da cidade, possui renda familiar de um a três salários mínimos, sua família vive no bairro São Marcos, cursa Dança na UFBA e é cotista, trabalha com projetos educacionais e com a banda de rap Munegrale.

Ana Paula Conceição Oliveira, rapper Azevixe, 24 anos, negra, soteropolitana, casada, mora com seu companheiro na Vila do Politeama, sua família é oriunda de Itapuã, e vive com dois a três salários, é pedagoga pela UFBA, pós-graduanda, trabalha como 
produtora da cultura hip-hop, foi vocalista da banda Simples Rap'ortagem.

Eliciana Santos Nascimento, militante do hip-hop Lis, 23 anos, negra, soteropolitana, casada, mora com o namorado no bairro de Ondina, sua família reside no bairro de Periperi, encontra-se sem renda no momento, é comunicóloga pela universidade privada Universidade do Salvador (UNIFACS), estudou sem bolsa de estudos, videomarker e produtora do filme "Hip-hop em quatro vidas”.

Priscila da Costa Lino, b-girl Nayala, 18 anos, negra, soteropolitana, solteira, oriunda do bairro de São Cristovão, não sabe informar renda, cursa ensino médio em escola pública, professora de break no Projeto Escola Aberta na escola pública de seu bairro. Sua mãe era contra seu trabalho com a dança break.

Vivian Quatuni, militante Olhasse, 25 anos, negra, soteropolitana, solteira, mora no bairro Uruguai com os sete irmãos, sendo ela a única filha; ela está sem renda no momento, e conta com a renda da família, entre dois e três salários; possui Ensino Médio e entende que a sua profissão é ser militante do movimento negro pelo Movimento Negro Unificado (MNU) e do hip-hop.

Dina Lopes, rapper Dina, 45 anos, negra, soteropolitana, solteira, mora com a filha única no bairro Sete de abril, cursou Teologia e atualmente cursa Ciência Sociais na modalidade EAD. É artesã de joias sem renda fixa e uma das primeiras rappers da cidade na banda Último trem; faz parte também do movimento rastafári ${ }^{31}$ e do movimento de economia solidária.

Mônica Reis, grafiteira Mônica, 28 anos, negra, soteropolitana, casada e mãe, mora no bairro São Caetano com marido (grafiteiro) e duas filhas. A renda do casal chega a quatro salários mínimos,

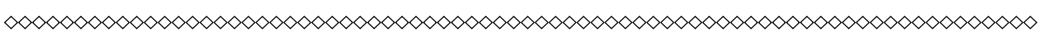

31 Entendo o movimento rastafári como um movimento que segue a filosofia "rasta", reproduzida pelas mensagens da música reggae e simbolizada pelos cabelos rastafari, como aspectos identitários religiosos e de posicionamento político de afirmação negra. Um dos maiores responsáveis pela divulgação desta filosofia foi o músico Bob Marley. 
possui ensino médio completo, trabalha no projeto "Salvador grafita" e tem reconhecimento internacional do seu trabalho.

Como se pode perceber, há entre elas uma heterogeneidade interna reconhecida pelas identidades de mães, lésbicas, solteiras, estudantes, graduadas, professoras, e outras entre as participantes. Essa diversidade se revelará na riqueza dos dados de pesquisa a serem analisadas sobre as convenções de gênero no hip-hop soteropolitano. 